\title{
PROJECT-BASED LEARNING AS A COORDINATION METHODOLOGY BETWEEN SUBJECTS IN A CHEMICAL ENGINEERING DEGREE
}

\author{
Carlos Carbonell1', Salvador C. Cardona1, Iván Domínguez¹, Vicent Fombuena1, \\ María Fernanda López-Pérez ${ }^{1}$, Jaime Lora1 ${ }^{1}$, Raquel Sanchís ${ }^{2}$ \\ ${ }^{1}$ Universitat Politècnica de València (UPV), Departamento de Ingeniería Química y Nuclear, \\ Escuela Politécnica Superior de Alcoy (SPAIN) \\ ${ }^{2}$ Universitat Politècnica de València (UPV), Departamento de Organización de Empresas, \\ Escuela Politécnica Superior de Alcoy (SPAIN)
}

\begin{abstract}
An important issue in any academic degree is to develop a high level of vertical/horizontal coordination between the different subjects taught along the four courses. This activity takes into account the coordination of the contents and methodologies that the teachers teach and the students acquire, the timing when the students learn them and the homework/exams that they do. As a result, both teachers and students gain an overall view of the degree and the teaching-learning process improves.
\end{abstract}

According to this idea, the teachers of the Chemical Engineering degree at Campus of Alcoy are participating in an Educational Innovation and Improvement Project (PIME) for applying the projectbased learning (PBL) methodology to the design of an adsorption system for the elimination of dyes in wastewater from the textile industry. This work is scheduled along the four courses and is distributed between some of the core subjects that the students attend. The adsorption column design is partially solved in each subject and the results obtained in one subject are used in the following. As a result, the project is completed sequentially throughout the degree applying a methodology based on teamwork.

This paper shows the activities proposed in different subjects, their timing and assessments during four courses. These activities include laboratory work for obtaining adsorption equilibrium and adsorption kinetics experimental data together with column dynamic performance. Other activities belong to the modelling and simulation domain for establishing the mathematical equations corresponding to the different phenomena linked to adsorption. Also, there are activities focused on experimental data treatment for estimating the parameters characterizing the adsorption isotherms or mass transfer coefficients. Finally, other activities are devoted to the column design and control, cost estimation, and oral/writing communication of the work done by the students.

Keywords: Adsorption, Vertical/Horizontal coordination, Project-based learning, PBL.

\section{INTRODUCTION}

Currently, professionals have to deal with situations characterized by great uncertainty, in which the information required for efficient decision-making is insufficient. This context requires professionals with different skills, both from a social, technical, practical, scientific and technological point of view. Today's professionals must face continuous changes as well as different industrial realities. They must also know how to efficiently manage critical situations. For this reason, based on the very dynamic competitive structure of the market and the hiring needs of the industry, companies increasingly require professionals with interdisciplinary experience. Due to all these challenges, the predominant model in higher education, based on master classes, is changing towards active teaching methodologies, in which the main actors are the students [1]. One of the active methodologies is Project-Based Learning (PBL). PBL is a learning approach to appropriately achieve more durable, deep and contextual learning results and outcomes for students [2]. PBL is described as engaging students in sustained, collaborative focus on a specific project, often organized around a driving question [3]. Students drive their own learning through inquiry, as well as work collaboratively to research and create projects that reflect their knowledge [4].

Many are those who point out the advantages of the PBL methodology. As early as 1991 Blumenfeld et al. [5] state that project increase students' interest because they involve students in solving authentic problems in working with others, and in building real solutions. For this reason, many universities opt for the PBL as a suitable learning method. One of these universities is Universitat Politècnica de València. 
The Vice-Rector's Office for Studies, Quality and Accreditation of UPV considers the integration of PBL into degrees as a priority to promote the learning of competencies (knowledge + skills + attitudes). Different studies have shown that active methods, including PBL, are the most compatible and consistent with competency training [6]. The Campus of Alcoy of UPV imparts six degrees: (i) Business Administration and Management; (ii) Electrical Engineering; (iii) Industrial Design and Product Development Engineering; (iv) Computer Engineering; (v) Mechanical Engineering; and (vi) Chemical Engineering. The current educational plans of these degrees contemplate, through their verification reports, a distribution of European Credit Transfer and Accumulation System (ECTS) credits in different typology of learning activities (Theory, Practical sessions, Seminar, Laboratory sessions, Computer sessions and Field Practices) by subjects. In recent years, many efforts have been made to promote horizontal and vertical coordination among all subjects. In this sense, the incorporation of PBL can provide numerous benefits, from the point of view of coordination between subjects and from the point of view of the students' learning process.

The Campus of Alcoy has launched an 'Institutional Educational Innovation and Improvement Project' (PIME) with the aim of implementing methodologies that promote active students' learning, through the incorporation of PBL in subjects of its Bachelors' degrees. Some of the PBL models defined within the frame of this PIME can be found in [7-10]. One of these degrees is Chemical Engineering whose main objective is to train professionals capable of designing, building, starting up and managing equipment and facilities in industries where there are chemical processes. This paper is focused on the design and implementation of PBL in such a degree.

The purpose of the PIME is to use PBL as a teaching methodology to improve the learning of our students. This methodology must combine the acquisition of knowledge with the acquisition of skills. In addition, students relate these projects to real professional problems if these activities have a suggestive design. This tool can be the connecting link between subjects, to facilitate their coordination. The proposed project is for the design of an equipment or process related to Chemical Engineering, the parts of which can be resolved in various subjects. The teachers who work on this project must be coordinated, both conceptually and sequentially, so that the problem has an adequate temporary development. These activities involve both horizontal and vertical coordination in the degree of Chemical Engineering [11].

Previous experiences such as PIME "Use of MATLAB as a didactic strategy and horizontal and vertical coordination between subjects of the Degree in Chemical Engineering" offer guarantees that a project based on PBL can improve the coordination of contents between subjects [12], [13].

\section{METHODOLOGY}

In this section, we indicate the different steps followed in order to develop a complex project that students solve partially in each subject and can be completed sequentially throughout the Chemical Engineering degree.

\subsection{Project selection}

The main objective considered when these cross-cutting projects are defined is that students, from the first year, become familiar with the intrinsic activities related to Chemical Engineering, among which process design stands out. On the other hand, other objective is that students know the various sectors related to the industry near the sphere of influence of Campus of Alcoy. With these constraints in mind, from a list of 12 several possible projects, the selected project has been "Design of an adsorption column for the elimination of colorants in wastewater from the textile industry".

\subsection{Temporary distribution of activities by subjects and courses}

Table 1 shows the 17 subjects involved in this PIME (from a total of 39 core subjects) distributed between 7 departments, the 17 activities proposed (one for subject), the 5 phases in which the project is divided (from project description to industrial plant) and its temporary distribution along 4 courses. Activity 0 corresponds to the presentation of the project to the first year students. Each activity is worked following teamwork methodology, by groups of 3 to 5 students. 
Table 1. Temporary distribution of activities by subjects and courses

\begin{tabular}{|c|c|c|c|c|c|c|c|c|c|c|c|c|c|c|c|c|c|}
\hline \multirow{2}{*}{\multicolumn{2}{|c|}{$\begin{array}{c}\text { Course/Semester } \\
\text { Subject }\end{array}$}} & $1 \mathrm{st} / \mathrm{A}$ & \multirow{2}{*}{\begin{tabular}{c|}
$1 \mathrm{st} / \mathrm{B}$ \\
$\mathrm{BIE}$ \\
\end{tabular}} & \multirow{2}{*}{\begin{tabular}{|l|l|} 
2nd/A \\
$C E F$
\end{tabular}} & \multicolumn{3}{|c|}{$2 \mathrm{nd} / \mathrm{B}$} & \multicolumn{2}{|c|}{$3 \mathrm{rd} / \mathrm{A}$} & \multicolumn{5}{|c|}{$3 \mathrm{rd} / \mathrm{B}$} & \multicolumn{3}{|c|}{ 4th/A } \\
\hline & & Math I GE & & & CKC & CEL I & MT & CEL II & SO & CEL III & PAS & $\mathrm{CPCI}$ & EOPS & English & CEIP & CPC II & CEP \\
\hline Project description & Act. 0 & & & & & & & & & & & & & & & & \\
\hline Adsorption equilibrium & & Act. 1 & & Act. 4 & Act. 5 & Act. 6 & & & & & & & & & & & \\
\hline Adsorption kinetics & & & & & & & Act. 7 & Act. 8 & & & & & & & & & \\
\hline Pilot plant & & & & & & & & & Act. 9 & Act. 10 & Act. 11 & & & & & & \\
\hline Industrial plant & & Act. 2 & Act. 3 & & & & & & & & & Act. 12 & Act. 13 & Act. 14 & Act. 15 & Act. 16 & Act. 17 \\
\hline
\end{tabular}

$\begin{array}{ll}\text { Math. I } & \text { Mathematics I } \\ \text { GE } & \text { Graphic Expression } \\ \text { BIE } & \text { Business and Industrial Economics } \\ \text { CEF } & \text { Chemical Engineering Fundamentals } \\ \text { CKC } & \text { Chemical Kinetics and Catalysis } \\ \text { CEL I, CEL II, CEL III } & \text { Chemical Engineering Lab I, II and III } \\ \text { MT } & \text { Mass Transfer } \\ \text { SO } & \text { Separation Operations } \\ \text { PAS } & \text { Process Analysis and Simulation } \\ \text { CPC I, CPC II } & \text { Chemical Process Control I and II } \\ \text { EOPS } & \text { Enterprises Organization and Production Systems } \\ \text { CEIP } & \text { Chemical Engineering Industrial Processes } \\ \text { CEP } & \text { Chemical Engineering Projects }\end{array}$

\subsection{Activity 0: Presentation of the project to first year students.}

This activity takes place when students are in their first year. In a seminar, teachers of the last courses are the ones who explain to all the students what the project consists of, what its context is and what they will get. It is important that the last year teachers make this presentation in order to show coordination between the teachers and that students become aware that its resolution will last four courses. The final objective and the importance of the process to be designed are also explained to them, in addition to giving them some short explanations of what will be developed in each subject. Obviously, this presentation cannot explain any concept that students are not yet ready to understand, but rather sets out the goals that they will be able to achieve at the end of their four-year academic journey. Special care will be taken in presenting the project so that it is motivating and enlightening about what a Chemical Engineer is intended to do, reinforcing the decision of those students who have chosen Chemical Engineering by vocation. The necessary audiovisual media (videos, Powerpoint, etc.) will be used.

The complete statement of the project is delivered to students in electronic format. Much attention is paid to the design of the project statement so that students know what they are going to do in each subject and what the expected results will be in each phase.

\subsection{Preparation of activities}

The description of the tasks to be carried out in each subject is realized by each teacher within their subject during class time, entering into the necessary details. A sheet is described later in which the teacher of each subject specifics the tasks to be solved to develop the activity proposed. Students work on these tasks throughout the course and their assessment is integrated into the assessment of the subject. Here is a brief summary of each of the activities.

\subsubsection{Activity 1}

In Mathematics I students apply numerical methods for determining the intersection between adsorption isotherms and the operation line with the aim of calculating the equilibrium concentrations in a batch tank.

\subsubsection{Activity 2}

Students plot the drawings corresponding to an industrial adsorption column in Graphics Expression. At this stage of the project, it is not possible to know the real dimensions of the column, because it has not been designed yet. Nevertheless, this activity can be done based on the fictitious dimensions provided by the teachers. 


\subsubsection{Activity 3}

In Business and Industrial Economics, through enterprise macroenvironment analysis, students apply Corporate Social Responsibility actions related to the environment, with the goal of preserving it and reducing impacts on society.

\subsubsection{Activity 4}

The application of mass balances, both steady-state and dynamic, to adsorption processes developed in both continuous stirred and batch stirred tanks is assigned to Chemical Engineering Fundamentals.

\subsubsection{Activity 5}

In Chemical Kinetics and Catalysis students apply adsorption isotherms to the kinetic study of heterogeneous reactions on solid porous catalysts.

\subsubsection{Activity 6}

This is mainly an experimental activity performed in Chemical Engineering Lab I, where students obtain adsorption equilibrium experimental data and estimate the fitting parameters of some adsorption isotherms studied in activity 5 , choosing the best one.

\subsubsection{Activity 7}

In Mass Transfer, the modelling of adsorption kinetics, considering both internal and external mass transfer, is performed. The best isotherm deduced in activity 6 is adopted in this modelling.

\subsubsection{Activity 8}

Other mainly experimental activity is accomplished in Chemical Engineering Lab II. In this case, students obtain adsorption kinetics experimental data and fit the corresponding internal and external mass transfer coefficients. The kinetic models used are those from activity 7.

\subsubsection{Activity 9}

In Separation Operations students simulate the practical and simplified models most used in the design and analysis of adsorption columns.

\subsubsection{Activity 10}

Chemical Engineering Lab III is reserved for experimentation with a pilot plant adsorption column. The obtained experimental data are compared with predictions done by simulating the simplified models studied in activity 9 .

\subsubsection{Activity 11}

In Process Analysis and Simulation students use a phenomenological model of the pilot plant adsorption column for simulating its temporary behavior. These theoretical results are compared with experimental data of activity 10 and predicted results of activity 9 , deciding finally the best model for analysis and design of adsorption columns.

\subsubsection{Activity 12}

Students define all the necessary instrumentation required by an industrial adsorption process in Chemical Process Control I: sensors, controllers and actuators.

\subsubsection{Activity 13}

In Enterprises Organization and Production Systems students determine the optimal location of a water treatment plant based on adsorption considering the location of wastewater suppliers. For this purpose, they use some methods such as weighted factors, center of gravity or location break-even analysis. Another task is the demand forecast determination of the raw materials necessary in the elimination of dyes in wastewater from the textile industry through projective forecasting methods. 


\subsubsection{Activity 14}

Students review the English terminology related to the fundamentals of the design and analysis of adsorption columns, make oral presentations and summarize relevant scientific papers connected with the most significant aspects of the project.

\subsubsection{Activity 15}

In Chemical Engineering Industrial Processes students design an industrial adsorption column using the best mathematical model deduced in activity 11, the wastewater properties specified in the project presentation and the desired outlet concentration.

\subsubsection{Activity 16}

Automation of four adsorption columns in series is assigned to Chemical Process Control II for optimizing the use of activated carbon. Both the design of the hydraulic installation and the design and implementation in a PLC of the algorithm necessary are undertaken by students.

\subsubsection{Activity 17}

Finally, in Chemical Engineering Projects, students make a comprehensive design of an adsorption industrial plant using all the partial results generated in the previous activities. Cost estimation and economic assessment of the process is another task considered.

Given that the core subjects end in the first semester of the fourth year, during the second semester each group prepare a poster that collects the entire design of the industrial plant carried out throughout their entire degree, which will be exhibited in the study center.

\subsection{Activity sheets}

Each teacher in the subject and within the class schedule makes a description of the activity to be carried out. The activity is detailed in a sheet, including the course, semester, schedule, skills acquired, evaluation and a description of the tasks that integrate the activity. Activities that have been carried out in previous subjects and are related to the current activity or that are carried out in subsequent subjects using the results generated in the present activity are also included in the document. The number of deliverables must be specified in each sheet as well as their planning.

The sheet can be the same for all groups of students or the teacher can make a sheet for each group. All the activities presented to the students during the courses should have a similar presentation format, so that they notice all the activities of the adsorption process as a single project.

It is important that an estimate of the time used to carry out the activities is indicated. The face-to-face and non-face-to-face hours must be differentiated. Each activity may need different times, although an agreement or consensus must be acquired by the teachers so that the weight of the project in each subject is as homogeneous as possible.

It is very important that students know which are the specific and transversal competences that they are going to work on in the activity, because in the future these competences will be evaluated by the companies. Therefore, these competencies are included in the sheet.

Finally, the assessment of the activities should be indicated. In this part, teachers should agree to evaluate in a similar way, although the percentage of the final grade could change in each subject. Fig. 1 shows the structure of the sheet that each teacher must fill out. 


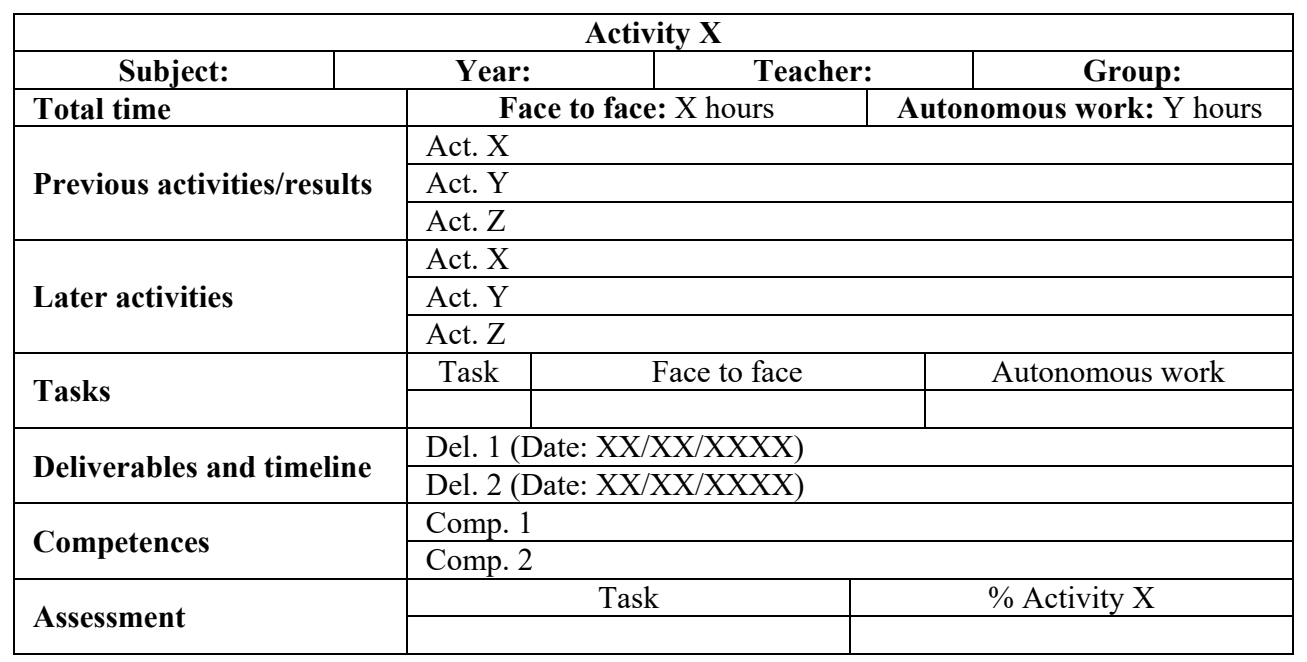

Figure 1. Activity sheet generic for a subject

\subsection{Surveys}

The most important challenges of this project are the coordination of the Degree in Chemical Engineering and increasing the motivation of the students so that they are able to face a real problem, similar to future professional problems. Surveys are a way to check that the objectives set in the project activities have been met, Table 2. These surveys also help the teacher to improve her activities and achieve better coordination with the other subjects.

Table 2. Example of a survey carried out in a subject within the project

\begin{tabular}{|c|c|c|c|c|}
\hline & $\begin{array}{c}\text { Very } \\
\text { dissatisfied }\end{array}$ & Dissatisfied & Satisfied & $\begin{array}{c}\text { Very } \\
\text { satisfied }\end{array}$ \\
\hline \multicolumn{5}{|l|}{$\begin{array}{l}\text { Global assessment of the approach and development } \\
\text { of the teaching methodology }\end{array}$} \\
\hline & Poor & Fair & Good & Excellent \\
\hline \multicolumn{5}{|l|}{$\begin{array}{l}\text { Assess the degree to which you consider that the PBL } \\
\text { methodology has helped you learn compared to more } \\
\text { traditional approaches }\end{array}$} \\
\hline $\begin{array}{c}\text { You consider that the use of the methodology } \\
\text { has helped you to: }\end{array}$ & Poor & Fair & Good & Excellent \\
\hline \multicolumn{5}{|l|}{ Understand theoretical content } \\
\hline \multicolumn{5}{|l|}{ Establish relationships between theory and practice } \\
\hline \multicolumn{5}{|l|}{$\begin{array}{l}\text { Relate the contents of the subject and obtain an } \\
\text { integrated vision }\end{array}$} \\
\hline \multicolumn{5}{|l|}{ Increase interest and motivation for the subject } \\
\hline \multicolumn{5}{|l|}{ Analyze situations of professional practice } \\
\hline \multicolumn{5}{|l|}{ Investigate on your own about the proposed work } \\
\hline \multicolumn{5}{|l|}{ Solve problems or offer solutions to real situations } \\
\hline \multicolumn{5}{|l|}{ Make decisions around a real situation } \\
\hline \multicolumn{5}{|l|}{ Develop your communication skills (oral or written) } \\
\hline \multicolumn{5}{|l|}{ Develop your autonomy to learn } \\
\hline \multicolumn{5}{|l|}{ Take a participatory attitude towards your learning } \\
\hline \multicolumn{5}{|l|}{ Improve your team work skills } \\
\hline \multicolumn{5}{|l|}{ Develop necessary skills in professional practice } \\
\hline \multicolumn{5}{|l|}{$\begin{array}{l}\text { The evaluation system followed has been adapted to } \\
\text { the methodology }\end{array}$} \\
\hline $\begin{array}{l}\text { If you could choose the next course, would you opt for } \\
\text { this methodology? }\end{array}$ & & & & \\
\hline
\end{tabular}




\section{RESULTS}

In this section, both the sheet (Fig. 2) and survey corresponding to Chemical Kinetics and Catalysis subject are shown as an example of application of the methodology above described.

The survey has been carried out on 2nd course/B semester students in Chemical Kinetics and Catalysis subject, in the first year of implementation of the PBL methodology. The results show that the answers of the students on the questions posed in the surveys have a great deviation. But even so, it follows from them that $\mathrm{PBL}$ is a methodology that they consider useful, although it is not enough to increase their motivation. Regarding the evaluation followed in the activity, they consider that it was not adequate. All these answers help us to reflect on the improvement actions that we can apply in the following year (Fig. 3).

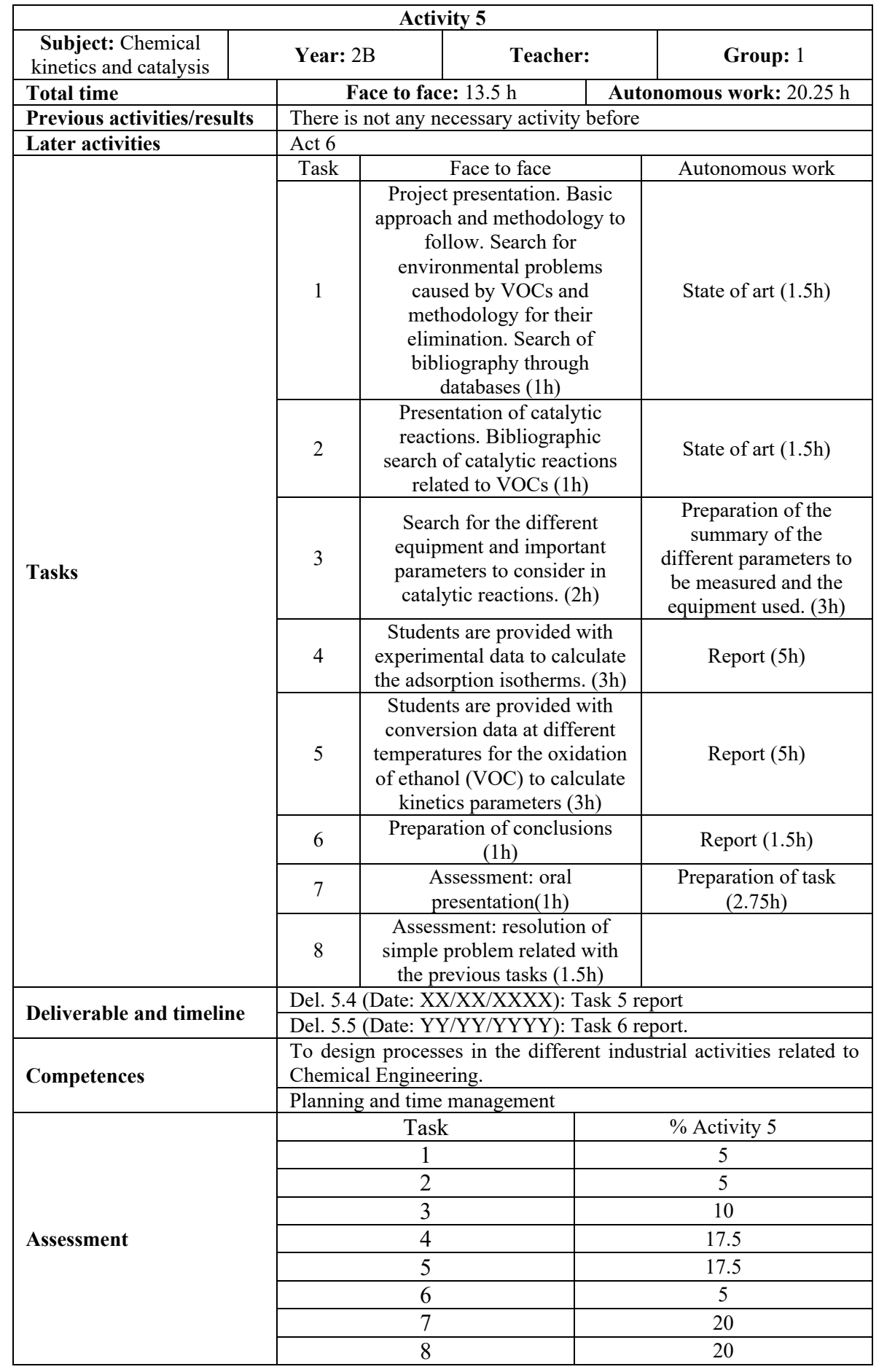

Figure 2. Chemical Kinetics and Catalysis sheet 
These improvement actions can be:

- First of all, we need to present the activity as a task that students can relate to the professional world so that they can notice its usefulness.

- We must also modify the methodology in the classroom, since autonomous work in class was the source of criticism from the students. They prefer the master class, since students consider that they waste less time, and notice that it costs them less to learn concepts.

- One should think about the documents delivered for autonomous learning and whether the project should be carried out in the classroom or, as it is done in most subjects, should be worked outside of class hours, since it seems that for them it is more useful.

- Regarding the evaluation, it will be necessary to reflect on how to modify it so that the students consider it adequate to the methodology, although without giving up an evaluation that rewards effort and the acquisition of competences.

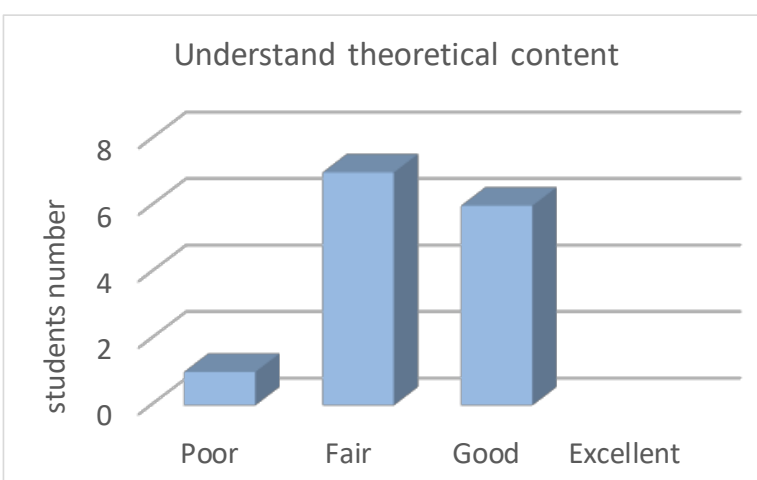

Analyze situations of professional practice

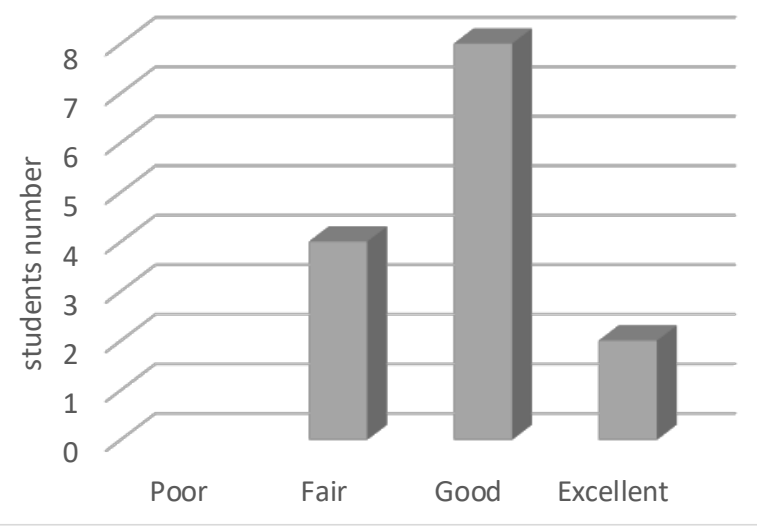

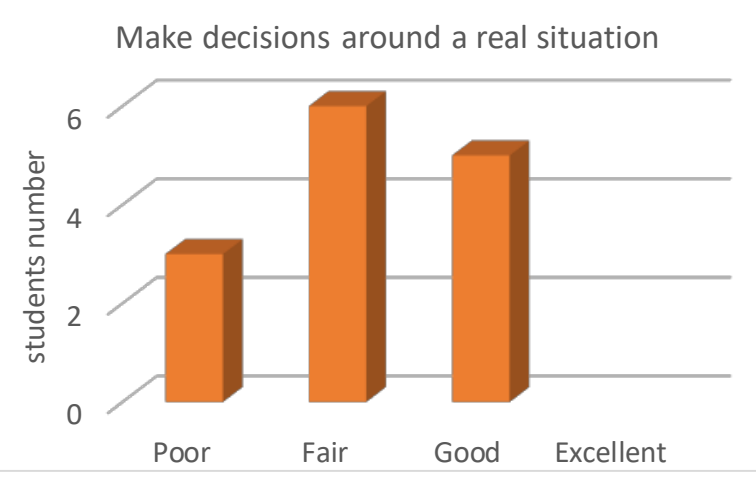

Solve problems or offer solutions to real situations

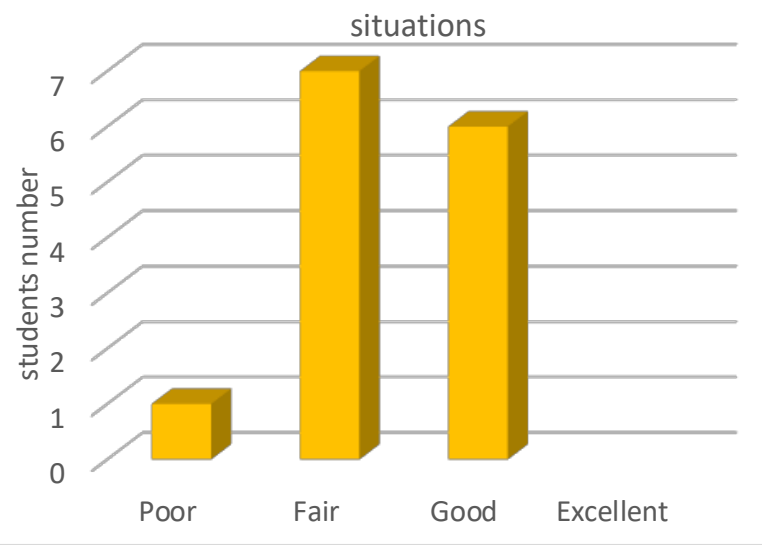

Figure 3. Chemical Kinetics and Catalysis survey

\section{CONCLUSIONS}

The implementation of the project "Design of an adsorption column for the elimination of colorants in wastewater from the textile industry" will help to improve the coordination of the Degree in Chemical Engineering, Campus of Alcoy, thanks to the joint work of different subjects. The presentation of all the activities proposed by the teachers shows that different subjects, that many times we consider that their contents are not related, can help to design a process.

Thanks to this coordination, students notice the degree as an achievement of steps and not isolated subjects, to obtain an end. The PBL allows students to develop the knowledge acquired in other subjects and to relate the concepts to industrial processes or real problems. Students will be able to face problems differently, because they will work differently, where the active part of the class is the student and not the teacher. On the other hand, the students will understand the role that each subject has in the degree and what competences they will need in their working life. This paper shows that the project must be supported by several subjects and therefore, different professors of the Degree in Chemical Engineering who must develop different tasks within the design project and that cover different concepts. 
Teachers must prepare sheets where the different tasks are detailed. These sheets will give detailed information to the students of all the work that must be done both in class and in homework

It is also necessary to evaluate the work done each year and analyse the opinion of the students. This opinion will help teachers to correct problems that may arise and improve the tasks and activities that they do. With the analysis of the different surveys it is possible to verify the achievement of the proposed objectives.

\section{ACKNOWLEDGEMENTS}

This article has been supported by Universitat Politècnica de València, particularly by the Vice-rectorate for Digital Resources and Documentation (Vicerrectorado de Recursos Digitales y Documentación) and Vice-Rectorate for Studies, Quality and Accreditation (Vicerrectorado de Estudios, Calidad y Acreditación) under the Call for Learning + Teaching (Convocatoria A+D2019: Aprendizaje + Docencia. Proyectos de Innovación y Mejora Educativa) and Project Code: A157. The authors would like to acknowledge the support of the Institute of Educational Sciences (Instituto de Ciencias de la Educación), the Evaluation and Monitoring Commission for Educational Innovation and Improvement Projects (Comisión de Evaluación y Seguimiento de Proyectos de Innovación y Mejora Educativa (CESPIME) and Escuela Politécnica Superior de Alcoy.

\section{REFERENCES}

[1] R. Sanchis, J. Mula, B. Cantó Colomina, D. Garcia-Sanoguera, J.I. Torregrosa López, "Diseño de la Incorporación del Aprendizaje Basado en Proyectos en las Titulaciones de Grado del Campus de Alcoy de la Universitat Politècnica de València", VI Congreso Nacional de Innovación Educativa y Docencia en Red, Editorial Universitat Politècnica de València, 2020.

[2] K. Gary, "Project-based learning", Computer, vol. 48, no. 9, pp. 98-100, 2015.

[3] S. Fincher, D. Knox, "The Porous Classroom: Professional Practices in the Computing Curriculum" Computer, vol. 46, no. 9, pp. 44-51, 2013.

[4] S. Bell, "Project-based learning for the 21 st century: Skills for the future", The clearing house, vol. 83, no. 2, pp. 39-43, 2010.

[5] P.C. Blumenfeld, E. Soloway, R.W. Marx, J.S. Krajcik, M. Guzdial, A. Palincsar, "Motivating projectbased learning: Sustaining the doing, supporting the learning", Educational psychologist, vol. 26, no. 3-4, pp. 369-398, 1991.

[6] F. Lasnier, F. Réussir la formation par compétences. Montréal: Guérin, 2000.

[7] M. Pérez-Sánchez, M. Díaz-Madroñero Boluda, J. Mula, R. Sanchis, "The Sustainable Development Goals (SDGs) Applied to Higher Education. A Project Based Learning Proposal Integrated with the SDGs in Bachelor Degrees at the Campus Alcoy (UPV)", EDULEARN Proceedings, pp. $3997-4005,2020$.

[8] R. Balart, N. Montanes, L. Quiles-Carrillo, S. Jordá-Gisbert, H.C. Sanchis-Gomis, Sanchis, R., "Model Design and Calculation with Polymeric and Composite Materials through Project-Based Learning", EDULEARN Proceedings, pp. 3979 - 3986, 2020.

[9] J. Linares-Pellicer, J. Orta-López, J. Salavert-Torres, M.J. Segura Flor, J.A. Silvestre Cerdà, R. Sanchis, "Towards Inter-Subject Project-Based Learning in Programming-Related Courses at Computer Science Studies", EDULEARN Proceedings, pp. 3973 - 3978, 2020.1

[10] J. Esparza Peidro, E.J. Golf Laville, J.J Izquierdo-Doménech, J.V. Tomas Miquel, R. Sanchis, "Definition of Project-Based Learning Models in the Computer Engineering Degree", EDULEARN Proceedings, pp. 3966 - 3972, 2020.

[11] S.C. Cardona, M.F. López-Pérez, J. Lora, "Aprendizaje basado en problemas en Ingeniería Química como metodología de coordinación vertical/horizontal entre asignaturas", IV Congreso de Innovación Docente en Ingeniería Química (CIDIQ), Santander. 2018.

[12] M.F. López-Pérez, S.C. Cardona, J. Lora, J., A. Abad, J.I. Torregrosa, "Resultados del Proyecto de Innovación y Mejora Educativa. Utilización de MATLAB como estrategia didáctica y de coordinación horizontal y vertical entre asignaturas del Grado de Ingeniería Química", Congreso IN-Red. 2015. http://inred.blogs.upv.es/ 
[13] M.F. López-Pérez, S.C. Cardona, J. Lora, J., A. Abad, "MATLAB as a tool as Analysis and Problem Solving Competency Development in Chemical Engineering Degree using MATLAB". Multidisciplinary Journal for Education, Social and Technological Sciences, 2016, http://dx.doi.org/10.4995/muse.2016.4623 